\title{
Multidimentional model in counseling to improve students self confidence
}

\author{
Sri Milfayetty ${ }^{1}$ \\ ${ }^{1}$ Universitas Negeri Medan \\ *Corresponding author, e-mail: sri.milfayetty@gmail.com
}

\begin{abstract}
There were some phenomen that the counselling for kinestetic student did not effective to improve their self confidence. The purpose of this study was to innovate the quality of counseling process through multidimentional model in improving students self confidence. The model was developed based on students self confidence. The method used research and development model of Borg and Gall. The procedures conducted were: i) premilinary survey to produce instrument to be used in assesing students need; (ii) designing counseling process; (iii) implementing and evaluating data were collected. The results indicated that the multidimentional model in counceling process could improve the students self confidence.
\end{abstract}

Keywords: Counseling, multidimentional model, kinestetic, student, self confidence

How to Cite: Milfayetti, S. (2019). Multidimentional model in counseling to improve students' self confidence. International Journal of Research in Counseling and Education, 3 (1): pp. 42-48. DOI: https://doi.org/10.24036/0072za0002

This is an open access article distributed under the Creative Commons 4.0 Attribution License, which permits unrestricted use, distribution, and reproduction in any medium, provided the original work is properly cited. $@ 2018$ by author.

\section{Introduction}

There were phenomenon that 25\% students in North Sumatera high school (Milfa, 2015) have low confidence and $15 \%$ of them were kinestetic. It was difficult for them to join the counselling session. They could not patient to sit and talk. They need to move and do something. To be able to accommodate this condition, the new model of counselling should have characteristics, such as flexible to allow student sit and talking, move and do something. Preliminary studies found that multidimentional model in counselling have been prove its practical efficiency. In general, this model improved the student self confidence.

Self Confidence is defined as a person's beliefs to be able to behave in accordance with their expectations and desires. In this definition implied positive attitude of the individual that enables him to develop a positive assessment, both to himself and to the situation he faces. As a form of feeling, self confidence is also referred to as self-esteem or self-image in the form of a through evaluative dimension of the self (Santrock, 1999). Confidence is influenced by individual psychosocial stages of development. Eric Ericson in Milfa (2015) describes the psychosocial development of adolescents are at the stage capable of achieving self-identity that includes the role, personal goals and uniqueness and self-characteristic. If not able to achieve these abilities individuals will experience confusion in the role that impact on the fragility of personality, so that there will be self-concept disturbance that is low self-esteem, self-idealism that is not realistic as happened to helplessness. The development of confidence is influenced by internal factors such as individual and external patterns of parenting and social interaction. Patterns of family, social interaction with family members, peers, teachers and other community members influence individual confidence. Hurlocks (1980) explains that the development of self-confidence in adolescence is influenced by family care patterns, age maturity, gender, physical appearance, family relationships and peers. Characteristics of people who are confident according to Waterman (1980) is a person who has the ability to work effectively, responsibly and mature in doing the tasks and future goals. Not too different from the opinion of Lauster (1978) mentions the characteristics of people who are confident is to have an attitude of unselfishness, tolerance, no need of recognition of others, always optimistic and not hesitant in making decisions. Gilmer (1978) adds that people who have confidence usually have the courage to face every challenge and be open to new experiences, thanks to his belief in his own ability. Other traits are: believing in his or her competence, not being compromised, daring to accept 
and resisting rejection, self-control, stable emotion, looking at the success or failure of your own business, not easily giving in to fate or circumstances and not dependent or expecting help from others. Having a positive outlook on yourself, others and situations outside of himself, has a realistic expectation of himself.

The preliminary study showed that most of counselling session did by talking in high school. It caused that counselling session did not effective to improve students' self confidence. The experience in doing multidimention model in counselling could make the counselling process flexible used directive and nondirective and also conscious and unconscious. This model was adapted from

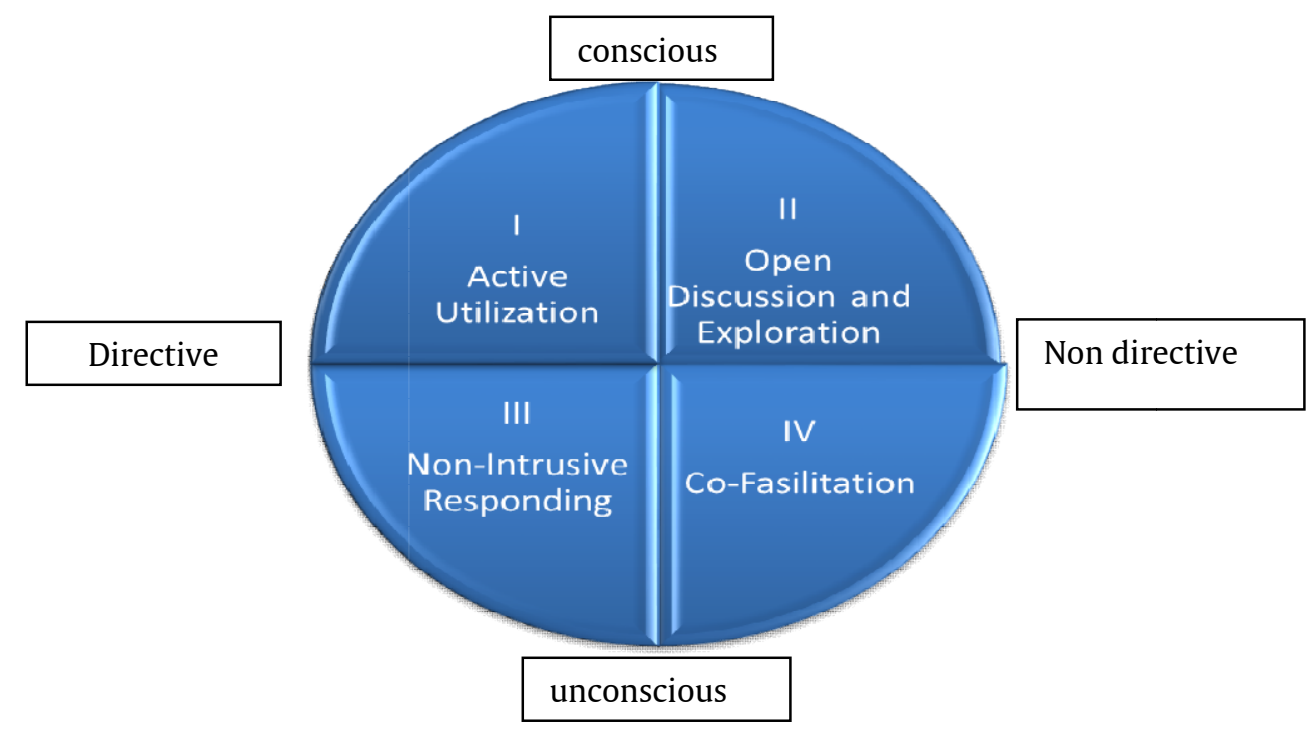

Figure 1: Multidimention Model in Counceling (Adaptation From Play Therapy Dimension Model) Source: Lorry and Gardner, 2012. Play Therapy Dimension Model.

Play Therapy Dimensian Model (PTDM). This model was developed by Lorri Yasenik and Ken Gardner based on Prescriptive Play Therapy described by Charles Schaefer (2003). Multidimensional model combines the theory and techniques of various play therapy approaches to help the spectrum of problems occur and enable an individual intervention plan. Multidimensional model helps counselors make judgments in the counseling and intervention process. This model gives the possibility of switching in the session: for example the client stops playing with a figurine metaphor and starts talking about the problem in the session. The framework of this model can be seen in Figure 1. The application of counseling in multidimensional model refers to the two principles described in two axes: directiveness and consciousness. Directiveness is related to immersion level and counselor interpretation level whereas consciousness is concerned with representation of client awareness in counseling and playing, and verbalization activities. Imersion levels are known from ongoing verbal counseling / discussions about the lives of clients. It is categorized low if there is no discussion whereas it is high if it becomes part of a session or outside session. The reflective statement is known from the counselor's behavior in following the students emotions, non-verbal behavior, playing activities and so on. It is categorized as low if done with irregular frequencies and is categorized as high if used more frequently. The emotional state of the counselor within Multidimentional model can be determined by reflection and response. It is categorized as low if it only observes the client and seldom reflects the student's emotions. Categorized moderate if sometimes a mirror to the student's emotions or characters the client plays. Highly categorized if given emotional response to curtail the student's emotional expression. The level of emotional involvement of the counselor in the session is categorized low if not emotionally and empathically involved. A moderate category when considering there are some feelings associated with the material presented by the client. High category if involved emotionally and connected with what the client submitted. The level of physical counselor involvement in playing either from touch or energy level, is categorized as low if virtually nonexistent, only observes the client, is not involved in the activity even when invited by the client. Medium category if physically involved only when invited and with a moderate contact. High category if physical involvement is frequent and close. The counselor can interpret the hypothesis by using the character to test it in play metaphor and directly declare in observation and bring consciousness consciously. It is categorized as low if it is not there at all. It is said to be formulating some hypotheses and using characters to test and make interpretations in play metaphors. Highly categorized if it 
directly states the observation or hypothesis to bring the issue / consciousness into consciousness. Interpretations are categorized as low frequencies if they never, only withstand interpretation and continue to use non-directive. Low category if occasionally make interpretive comments and high category if often give interpreation. The level of interpretation is called reflective if reflection comments observe relationships, motives and behaviors through characters or themes. For example: "They look angry". The level of interpretation is called linking if the comments given directly to the game theme at that time aim to know the students' experience in the past or present. Eg: " Is that what you feel when ... ". The interpretation level is called bridging if comments are made to mobilize internal sources by sparking similarities between the theme of play with the previous session by bridging and recording the meaning of the theme and experience of the client story. Eg: "It seems they are trying to .... Like time ... ". From one way of thinking to another .. Now like this, like that ... .. from one reflection to another reflection. The characteristics of each quadrant can be identified from quadrants one through four. Quadrant I is Active Utilization: Consciuous-Directive. Characteristics such as: the initiative client to play, intermittent counselor reflection evokes the conscious response from the client, the therapist enters the play and develops the client's awareness, usually used instantaneously in limited-time situations, interpretive comments help clients recognize the consequences, behaviors and mind-pikes. Quadran II is open discussion and exploration: conscious directive. Characteristics: counselors take the initiative and structuring play activities in accordance with the problem of children. Using a sensitive and cognitive approach. Processing the students' issues consciously. Activity: board games, role play, feeling card games, sand play re-enactment/invite. Quadrant III non intrusive responding is unconscious-non directive. Characteristics include: students' take the initiative and immediately play. Counselors can be involved by responding reflectively and does not interpret, or talk about what happened, nor about the theme or issue that occurred. If the counselor comes to play it because of the invitation and direction from the student. Using the power / capability of the client to process, through play and without structured intervention, counselor attendance is essential, counselor follow and analyze themes / sequences that occur after the session. Quadran IV Co-Fasilitation: Unconscious Directive. Characteristics such as: initial initiative to play on students who lead. Counselors enter in play when invited. Counselors follow the theme and play patterns of students. Helping to stay on in play (incomplete segment) or compulsive repetition occurs. Testing hypotheses or elaborating play activities by giving comments, actions and subtle interpretations: in the context of play. Counselors can introduce new figures or other "tools" to unlock new things in the student, but not directly discuss or interpret.

How multidimentional model in counseling could improve self confidence? Self Confidence is a belief someone to be able to behave in accordance with expectations and desires. Characteristics of someone who has self confidence, among others: dare to face challenges, open to new experiences, believe in his competence, not compromised, dare to accept and face rejection, have self-control, emotions stable, look at the success or failure of his own business, surrender to fate or circumstances and not depend on or expect the help of others. Having a positive outlook on yourself, others and situations outside of himself, has a realistic expectation of himself. Someone who lacks self confidence will judge her lack of ability. This negative assessment will hinder the effort to be made to achieve the goal. Such negative views and judgments cause the individual to not do any activity with all the capabilities it has. As a result achievement is not as expected. Self confidence becomes the main mediator that drives someone to excel. Self confidence can be upgraded from inadequate and good conditions. One way that can be done is to conduct counseling. For individuals with kinesthetic style counseling is needed that can make it flexible to move and talk. In addition, for teenage clients in accordance with the stage of psychosocial development is to get a self identity requires a figure who can represent and at the same time become a figure of self identification in the face of the problem. The counseling process that is thought to be suitable for implementing is multidimentional model as it provides an opportunity for clients to express themselves through verbal or through metaphors both on the conscious and unconscious levels. Likewise, the counselor has the flexibility to adjust his involvement (immersion) directive-non directive. The multidimentional model process is performed in an integrated manner with the play process that takes place in the quadrant that matches Quadran I is Active Utilization: ConsciuousDirective. Quadran II is open discussion and exploration: conscious directive. Quadrant III non intrusive responding is unconscious-non directive. Quadran IV Co-Fasilitation: Unconscious Directive. Based on this explanation then multidimentional model will be efficacious in improving student self confidence. Metaphor will be effective in bridging the conflicts within its unconscius and consciousness. So there is a transformation within the client.

\section{Method}

Guidance and Counseling recently starts to develop from examining the micro level (individual, group, and family) to macro level (community) because to be able to understand the counselee $\mathrm{s}$ problem correctly, it is necessary to understand the social, cultural, and political contexts contributing to the problem 
(Arifin \& Zaini, 2014). Thus, guidance and counseling studies require other scientific disciplines (e.g. theology, philosophy, arts, and other sciences) and are required to be studied by other experts.

Counseling is considered as applied science. Therefore, investigating the local wisdom is very important. Some guidance and counseling experts have offered to give this practice a space for local culture values. One approach to counseling based on Indonesian culture is that from values in ancient manuscripts (codex) spread in the archipelago. One of which is from Sanghyang Siksakandang Karesian (SSK) manuscript.

Efforts to assess the personal characteristics of counselors in the SSK manuscript as one of these local wisdoms use hermeneutical studies under guidance and counseling perspectives. Thus, this study is considered as indigenous guidance and counseling studies. Indigenous guidance and counseling presents an approach in context (family, social, culture, and ecology), and its contents (meaning, value, and belief) are explicitly incorporated into the research design (Kim, Yang, \& Hwang, 2010).

This study concerns mainly on meaning and interpretation of SSK manuscript related with ideal character of counselor. Hermeunetics is qualitative research type that focus on human experience in comprehension pursuit about an object. The hermeunetics is defined as comprehension study, especially comprehension on text (Palmer, 1969).

For understanding some values in SSK manuscript, it needs interpretation device. It then underlies using hermeunetics method as the blade analysis (Palmer, 1969; Hidayat, 2011) to comprehend SSK manuscript. The researcher uses principle of Gadamer Hermenetics as dialogical process that emphasize more on reader (researcher) interaction process with text subject (SSK manuscript).

In this interpretation process, as Gadamer said, interaction occurs between interpreter (researcher) and text. Gadamer called it as dialogical process, it is a perspective that emphasize on interaction process between research and text (Valdes in Rahardjo, 2010). The process forms a cycle that described as part-whole logic.

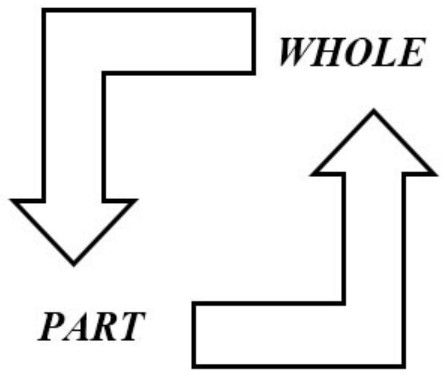

Figure 1. The Hermeneutics Cycle

The Figure 1 describes that the interaction process between (research) and text is the most important thing in Gadamer hermeneutics perspective. But, for research needs, the steps need to be modified in order to be more applicable. Therefore, the researcher applies some steps of data analysis that adopted from Patterson \& Williams (2002) that using code system. The system shape of organizing data is presented in Table 1.

Table 1. The System of Organizing Data

\begin{tabular}{lll}
\hline Original Text & Translation & Code \\
\hline Jaga rang dek luput ing na pancaga/n/ti, & Beware to avoid the pancagatı (five & $5: 1$ \\
sangsara. Mulah carut mulah sarereh, mulah & moral deficiencies) in order not to be & \\
nyangcarutkeun maneh. Kalingana & suffer, don't be treacherous, don't be \\
nyangcarutkeun maneh ma ngaranya: nu & deceitful don't be self-betrayed. Self- \\
aya dipajar hanteu, nu hanteu dipajar waya, & betrayed is saying wrong to correct \\
nu inya dipajar lain, nu lain dipajar inya. & $\begin{array}{l}\text { something, saying correst to wrong } \\
\end{array}$ & \\
& something. & \\
\hline
\end{tabular}

Description: The code of 5:1 means that data is found on page 5 , number 1 .

The research focuses on text study that describe some features of personality value of counselor that is revealed in SSK manuscript. The text that is studied as the object of research is SSK manuscript which has been translated and booked by some culture expert and Sundanese ancient manuscript. As primer data source, the researcher uses only one book in order for ease in reading SSK manuscript. The book that used is 
titled: Sewaka Darma (Kropak 408), Sanghyang Siksakandang Karesian (Kropak 630), Amanat Galunggung (Kropak 632): Transkripsi dan Terjemahan that is arranged by Danasasmita, Ayatrohaedi, Wartini, \& Darsa, published in 1987. The book is not the latest, but as far as the findings, there is not newest translation book SSK manuscript yet except the book mentioned above.

The seconder data source that is used in this research consists of some literatures that related with research object and data such as interview result, discussion with some stakeholders that considered have comprehension related the research object.

The method used in this study was research and development which was adopted from Borg, Walter (1983). The procedures were as follows: (i) preliminary survey, (ii) model development, (iii) model testing, (iv) model validation, and ( $\mathrm{v}$ ) model socialization. This method was done in three stages. A preliminary survey conducted was data collecting on kinaesthetic students and self confidence. Data collection was performed through self confidence assesment software. The data obtained were descriptively analysed to be further used in mapping students self confidence. Multidimensional model in counseling based on students self confidence was resulted from the preliminary survey. The research question was: how does the Multidimensional Model in Counseling improve the quality of students self confidence ? Population in this study was student in High School in Deli Serdang in grade 10 about 80 students and kinaesthetic 12 person. Sample was collected randomly for 6 kinesthetic student with very low self confidence.The instrument used to collect the data were self report of the students and software. Collected data were analyzed using percentage method, in addition, students self confidence by using software application. The procedure in these study in Table 1

Table 1 : The Procedure of Study

\begin{tabular}{|c|c|c|}
\hline Activities & Method & Goal \\
\hline \multicolumn{3}{|l|}{ First Year : 12 month } \\
\hline \multicolumn{3}{|l|}{ 1. Preliminary Survey } \\
\hline $\begin{array}{l}\text { Need Assesment: } \\
\text { Student Self confidence } \\
\text { Indicator: } \\
\text { self-esteem, optimistic, } \\
\text { objective, responsible, rational } \\
\text { and realistic beliefs }\end{array}$ & $\begin{array}{l}\text { Use Software to collect } \\
\text { data }\end{array}$ & $\begin{array}{l}\text { Base line data to } \\
\text { design MDM in } \\
\text { Counselling }\end{array}$ \\
\hline \multicolumn{3}{|l|}{ 2.Model Design } \\
\hline $\begin{array}{l}\text { MDM in counselling need } \\
\text { identification } \\
\text { Designing the procedur of } \\
\text { counseling } \\
\text { Media in counselling: drawing, } \\
\text { sand, clay, puppet, mask, } \\
\text { music, role play etc. } \\
\text { Try Out }\end{array}$ & $\begin{array}{l}\text { Analysis to : } \\
\text { Preliminary survey } \\
\text { report } \\
\text { Expert judgement }\end{array}$ & $\begin{array}{l}\text { Designing the } \\
\text { procedur of } \\
\text { counseling } \\
\text { Try Out Model result } \\
\text { Model revised }\end{array}$ \\
\hline \multicolumn{3}{|l|}{ Second Year : 12 month } \\
\hline \multicolumn{3}{|l|}{ Try out Model at school } \\
\hline Model validation & $\begin{array}{l}\text { Multidimensional model } \\
\text { in counselling }\end{array}$ & $\begin{array}{l}\text { Multidimensional model } \\
\text { in counselling } \\
\text { training for counsellor }\end{array}$ \\
\hline Socialyzing the model & Workshop & Activities report \\
\hline Study report & Study analysis & The result of the model \\
\hline
\end{tabular}

\section{Results}

This graph shows that self confidence issues in subjects before multidentional model in counselling tend to be higher than after counseling. 


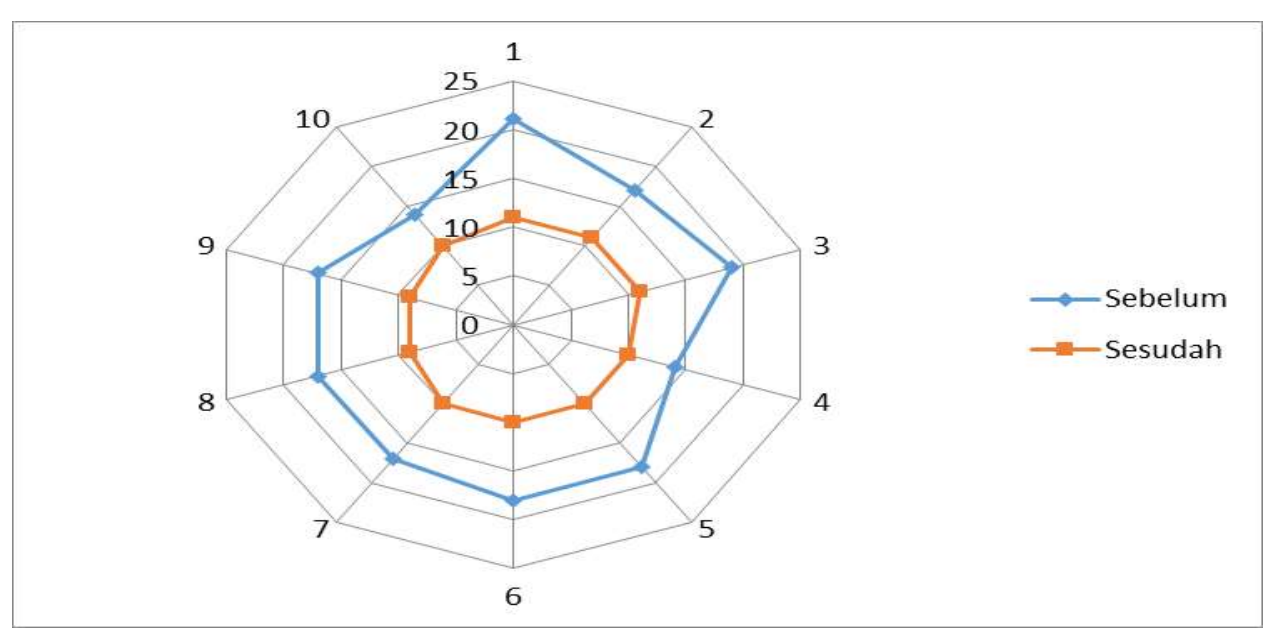

Figure 1: Graph of self confidence data differences in pretest and posttest

From figure 1: Graph of self confidence client data Differences in pretest and posttest results were seen using a descriptive quantitative percentage analysis by comparing the scale of the results of data analysis of each pretest and posttest subjects. The result of comparison shows the total score of self confidence score between pretest and posttest both on subject $A$ and in subject $B$. This means an increase in self confidence. Based on the scale of self confidence $A$ subject has increased as well as subject B. Based on the self confidence dimension, both A and B subjects experience better condition than before. Discussion The results showed that multidimentional model can improve self confidence. Subjects change from low self confidence to normal. The change from the irrational and realistic conditions of his self image becomes rational and realistic about his image image. In the pre-counseling activity subjects selected several figurin, so that the subject metaphor (Ed.Jacob, 1974) can be known. In the process of examining subjects mapping the strengths and limitations of the multidimentional model which can then be understood as a projection of the state of the subject. Through the process of creative visualization and drawing, subjects can project the rationale and reality of their self-image. At the end of subject counseling can re-orientation and self-reorientation (Adler in Dreikurs 1967) so that self image about itself changed to be rational and in accordance with reality. Multidimentional model that gives chance to kinaesthetic subjects to play (according to kinesthetic characteristics) during counseling process. The result is that subjects become more positive about themselves, talk and act with confidence, become active and enthusiastic, help others without expecting any rewards as well as maintaining self-image. Learning from the metaphor stories, subjects can reorient themselves through multidimentional model so that subjects experience changes in self confidence: selfesteem, optimistic, objective, responsible, rational and realistic beliefs (Lauster, 1987). Changes occurring to clients through multidimentional model can be understood through the mutidimentional model that counselor involvement in counseling / playing activities is influenced by the relationships established in each session between the counselor and the client with quadrant flexibility resulting from the relational aspect established between the counselor and the client. Each session is facilitated by showing empathy response, genuine presence, a new in-depth and secure relationship. This condition helps clients become better able to deal with emotional, psychological, and relational distress issues. This aspect is manifested because the multidimentional model creates a secure and protected relationship. Such relationships produce trust which is the self-confidence that the individual needs to be able to move or improve oneself in a better direction. These aspects enable clients to build trusts, explore and access unconscious issues that can not be worded with words and correct them. It also enables a person to learn to accept himself, unleash a defense mechanism in an unhealthy self and fix it. Freedle (2017) says a safe physical and emotional experience allows for trust, lower defenses and calming the nervous system. Siegel (2010) suggests that therapeutic relationships will also help the process of rewiring broken neural circuits within the system in the brain and establish a healthier connection pattern. Relational conditions, beliefs and relationships that will then build and improve perceptions in the mind, affection and actions or responses that are not effective. Increased and realized individual awareness through quadrant migration sessions helps clients see the issue of intrapsychic conflict more clearly. This improved aspect of consciousness occurs because of counseling and playing with a superhero metaphor to present a new awareness by activating all the experiences stored in the unconscious or repressed memories in unsconception to be brought to consciousness. This results in awareness or awareness of unfinished conflicts and less effective defense mechanisms in the face of pressure or stressors 
and resolving them. In addition, the expanding awareness aspect is also created through repetition in the use of superhero figurines. Repetition of this picture helps individuals summon memories that are pressed in the subconscious (Long term memory) to be re-observed and repaired. Repetitions in the mutidimentional model process also affect.

\section{Conclusions}

The results showed that mutidimentional model can improve self confidence. Subjects change from low self confidence to normal. The change from the irrational and realistic conditions of his self image becomes rational and realistic about his image image. In accordance with the results of this study can be stated that multidimentional model in counsellling can increase students self confident with kinesthetic style. In other words mutidimentional model in counselling counselling efficacy to alleviate the problem of self-confident kinaesthetic clients.

\section{References}

Anderson,K,\&Gavallaro.D. (2002). Parents or Pop Culture. Heroes and Role models. Childhood Education, 78, 181-189.

Bandura, Albert. 1998. Personal and Collective Efficacy ini Human adaptation and Change. Jurnal. California, USA. Stanford University.

Chesley, Gayle et all.2008. Verbal and Non Verbal Metaphor with Chldren in Counseling. Journal of counseling and Developmen. 86 Fall. 399-411.

Dreikers,R.\&Soltz,V. (1964). Children : The challenge. New York : Howthorne/Dutton.

Fingeroth, D. (2004). Supermen on the Couch. What Superhero Tell us about Ourselves and Our culter.New York.Continum Book.

Landreth, G.(2002) Play Therapy. The Art of Play Therapy (2 nd). Newyork : Brunner and Roudledge.

Lawren C. Rubin (2007).Using Superhero in Couseling and Play Theraphy. New York : Springer publishing

Lawrence, Rubin. 2008. Popular Culture in Counseling, Psychoterapy, And Play Based Intervension. New York : Springer Publishing Company.

Kottman,T. (1995). Partners in Play : An Adlerine Approach to Play Therapy. Adlerian Approach to Play Therapy Alexandria.VA :American Counseling Association.

Moris,T\&Morris.M.M.Eds.(2005).Superheroes and Philosophy : Truth, Justice and Socratic Way. La Selle.IL: Open Court Press.

Milfayetty. (2015). Konseling Intensif dengan Superhero. Medan : YRP

Prayino, (2015). Konseling Integritas. Jogjakarta : Paramitra Publising. Prayitno dan Marjohan (2015). Pelayanan Profesional Konseling yang Berhasil . Bandung : Mujahid Press.

Wickman,S.A.Daniels.M.H.White,I.J.\&Fesmire,S.A. (1999). A Primer in Conceptual Metaphore for Counselor. Journal of Counseling and Development. 